\title{
Okullarda Yenileşme İklimi Ölçeğinin Geçerlik ve Güvenirlik Çalışması
}

\author{
DOI: 10.26466/opus.533385 \\ * \\ Mahmut Polatcan* \\ *Dr, Karabük Üniversitesi, Edebiyat Fakültesi, Karabük / Türkiye \\ E-Posta: mahmutpolatcan78@gmail.com ORCID: 0000-0002-5181-0316
}

Öz

$B u$ araştırmanın amacı, okullarda yenileşme iklimi ölçeğini geliştirmektir. Ölçek madde havuzunun oluşturulmasında yenileşme iklimi alanyazınındaki yenileşme ve yaratıcı iklim modellerinin yanı sıra geliştirilen ilgili ölçekler referans alınmıştır. Ölçme aracının madde havuzu alan uzmanlarının görüşleri doğrultusunda taslak forma dönüştürülmüştür. Taslak ölçek formu, Ankara İli Yenimahalle ilçesinde görev yapan 193 gönüllü öğretmen üzerinde uygulanmıştır. Açımlayıcı faktör analizi sonuçlarına göre, yenileşme iklimi ölçeğinin KMO değeri .94, Bartlett Küresellik testi değeri 6243.07'dir ( $p=.00$ ). Ölçek, varyansın \% 73.23'ünü açılamaktadır. Ölçek maddelerinin faktör yük değerleri .49 ile .88 arasında değişmektedir. Analiz sonucunda 6 boyuttan oluşan 42 maddelik ölçek; yenileşmeye destek, kaynaklar ve olanaklar, inisiyatif alma, yenileşmeye açıklık, takım çalışması ve uyum boyutlarından oluşmaktadır. Ölçeğin Cronbach Alpha güvenirlik katsayısı .95'tir. Düzeltilmiş madde toplam korelasyonları ise .59 ile .86 arasında değişmektedir. Ayrıca uygulanan doğrulayıcı faktör analizi sonuçları açımlayıcı faktör analizi sonuçlarım desteklemektedir ( $X^{2} / S d=1.65, R M S E A=$ $.051, G F I=.86, A G F I=.83, C F I=.97)$. Yenileşme iklimi ölçeğinin geçerlik ve güvenirlik sonuçlarma göre, ölçeğin okullarda yenileşme iklimini ölçen bir araç olduğu ifade edilebilir.

Anahtar Kelimeler: Yenileşme, Yenileşme iklimi, Okul 


\title{
Innovativeness Climate in Schools Scale Validity and Reliability Study
}

\begin{abstract}
This research aims to develop a innovativeness climate in school scale. The scale was applied to 193 working teachers in high schools at Yenimahalle District, Ankara. According to the exploratory factor analysis results, KMO value of innovativenes climate scale is .94 and the Bartlett Spherity test value is 6243.07 ( $p=0.00$ ). It is explained that variance of the is scale $73.23 \%$. After the exploratory factor Analysis, the scale included 32 items and five factors. These factors were labeled as support for innovation, resources and opportunities, taking initiative, openness to innovation, teamwork and adjustment. In Scale the Cronbach's alpha coefficient for the whole scale was found to be .95. In addition, confirmatory factor analysis results is supported the exploratory factor analysis results. (Chi-square/Sd=1.65, RMSEA $=.051, G F I=.86, A G F I=.83, C F I=.97)$. The findings of the study revealed that the scale was a valid and reliable instrument for measuring innovativeness climate.
\end{abstract}

Keywords: Innovativeness, Innovativeness climate, School 


\section{Giriş}

Örgütler, güncel gelişmelere ayak uydurmak için dönemin koşullarına göre yenilikler yapmaktadır. Günümüzde yenileşmeyi tetikleyen önemli unsurların başında bilgi ve teknolojideki gelişmeler gelmektedir. Bu gelişmeler, örgütlerin mevcut durumunu iyileştirme ve yenilik yapma gereksinimini doğurmuştur (Chen, Huang ve Hsiao, 2010; Somech ve Drach-Zahavy, 2011). Yenileşme, problemin tanımlaması ile başlayan yeni fikir ve düşüncelerin oluşturulmasıyla devam eden (Scott ve Bruce, 1994) yeni düşünce ve davranışların örgüt tarafından benimsenmesi ile sonuçlanan aşamalı bir süreçtir (Damanpour, 1992). Yenileşme, araştırma ve geliştirme dışında çalışma ortamında da gerçekleşebilmektedir (Oldham ve Cummings, 1996). Bununla birlikte yeniliklerin uygulanmasında, örgüt paydaşlarının tutum ve davranışları önemlidir (Ren ve Zhang, 2015). Bu çerçevede örgütlerde yenileşme sürecinde çalışanların yenileşmeye ilişkin tutum ve davranışlarını etkileyen faktör yenileşme iklimi olarak ifade edilmektedir. Araştırmacılar örgütlerde çalışanların yenilikçi davranış ve uygulamaları benimsemesi ve hayata geçirilmesinde yenileşme ikliminin önemine vurgu yapmaktadırlar (Amabile, Conti, Coon, Lazenby ve Herron, 1996; Ekvall, 1996; Jaiswal ve Dhar, 2015; Moolenaar, Daly ve Sleegers, 2010; Remneland-Wikhamn ve Wikhamn, 2011). Yenileşme iklimi yenileşmeye destek, kaynak ve olanaklar, paydaşların inisiyatif alması, yenileşmeye açıklık, takım çalışması ve uyumu kapsamaktadır (Amabile vd., 1996; Ekvall, 1996; Hunter, Bedell ve Mumford, 2007). Bu bağlamda örgütlerde yenilikçi uygulamalarının yaşama geçirilmesinin temelinde çalışanların tutum ve davranışlarının etkili olduğunu göstermektedir.

Yenileşme iklimi araştırmalarında yenileşme ile yaratıcllık iklimi birlikte kullanılmıştır (Mathisen ve Einarsen, 2004; West ve Sacramento, 2012). Araştırmacılar, yenileşme sürecinde fikirlerin üretildiği yaratıcılık ve yaratıcı fikirlerin uygulanması aşamalarına odaklanmıştır (George ve Zhou, 2001; Somech ve Drach-Zahavy, 2011). Bu kapsamda araştırmacılar, örgütlerde yenileşme ikliminin ölçümü için birçok model ve ölçme aracı kullanmışlardır. Örneğin Amabile Conti, Coon, Lazenby ve Herron (1996), yaratıcılığın teşvik edilmesi, özgürlük ve özerklik, olanaklar, baskı, yaratıcılık için örgütsel engeller boyutlarından oluşan KEYS 
modelini geliştirmişlerdir. Ekvall (1996), meydan okuma, özgürlük, fikir desteği, dinamizm, mizah, tartışmalar, uyuşmazlık ve risk alma gibi boyutlardan oluşan yaratıcı iklim modelini oluşturmuştur. Anderson ve West (1996), takım iklimi ve yenileşme ilişkisini incelediği takım iklimi envanteri; fikir zamanı, vizyon, katılımcllık, göreve yönelim ve yenileşmeye destek boyutlarını kapsamaktadır. West ve Sacremento (2012), yaratıcı iklim ve yenilik için, paylaşılan vizyon, güven, görev yönelimi, karara katılım, çatışmayı yönetme, esneklik bağlamında ele almıştır. Siegel ve Keammerer (1978), yeniliğe destek algisı modelinde; liderlik, normların farklılığı, gelişimin sürekliliği ve tutarlılık boyutlarını kullanmıştır. Scott ve Bruce (1994) yenileşme iklim modelini, yeniliğe destek ve kaynak sağlama boyutlarıyla sınırlandırmıştır. Montes, Moreno ve Fernandez (2004) yenileşme iklimi modelini destek, baskı, uyum, tanıma, tarafsızlık olarak boyutlandırmışlardır. Bu kapsamda mevcut araştırmada yukarıda değinilen yenileşme iklimine ilişkin geliştirilen model ve ölçeklerden yararlanılarak oluşturulan yenileşme iklimi ölçeği; yenileşmeye destek, kaynaklar ve olanaklar, inisiyatif alma, takım çalışması ve uyum, yenileşmeye açıklık boyutları çerçevesinde incelenmiştir.

Yenileşme iklimini etkileyen faktörlerin başında çalışanların yenileşmeye desteği veya teşviki gelmektedir. Yeniliklere değer verilmesi, yenilikçi fikirlerin ödüllendirilmesi, yaratıcı fikirlerin yönetim tarafından kabul görmesi ve yenilikçi fikirlerin çalışanlarca paylaşılması yenileşmeye desteğin ön koşulları arasındadır (Amabile vd., 1996; Ekvall, 1996; Hunter vd., 2007; West ve Sacramento, 2012). Ayrıca örgütsel teşvik, çalışma grubu desteğini çalışanların motivasyonunu etkilediğini ve böylece çalışanların yaratıcı düşüncelerini ortaya çıkarmaya olanak tanımaktadır (Amabile, 1983; Hunter vd., 2007). Yenileşme iklimi için çalışanlara sunulan inisiyatif önemlidir. İnisiyatif alma, çalışanların risk alması, yaratıcı düşünce için özgürlük ve özerklik tanınması, karar alma süreçlerine katılması ve hataların bir öğrenme fırsatı olarak görülmesi şeklinde değerlendirilmektedir (Ahmed, 1998; Amabile vd., 1996; Anderson ve West, 1996; Ekvall, 1996; Remneland-Wikhamn ve Wikhamn, 2011). Yenileşme uygulamalarının yaşama geçirilmesinde örgütsel kaynak ve olanaklara ihtiyaç duyulmaktadır. Yenileşme için gerekli araç ve gereçlerin temini, yenilikler için tanınan zaman, sunulan fırsatlar ve 
alınan hızlı kararlar yenileşmeyi kolaylaştırmaktadır (Amabile, 1996; Montes vd., 2004). Örgüt çalışanlarının işbirliği yapmaları ve uyum içerisinde çalışmaları yenilikçi düşünceye katkı sağlamaktadır. Takım çalışmaları çalışanların yaratıcı düşüncelerini paylaşmaları, beyin fırtınası yapmaları, problem çözmeleri ve farklı düşüncelerini ortaya koymaları açısından önemlidir (Damanpour, 1992; Ekvall, 1996; West ve Sacramento, 2012). Örgütlerde yenileşme uygulamalarının başarısında çalışanların değişime açık olmaları da önemli yer tutmaktadır. Yenileşmeye açıklık, çalışanların gelişime açık olmaları, statik duruma meydan okumaları ve yeniliklerin sonuçlarının olumlu olacağına dair inançlarını kapsamaktadır (Anderson ve West, 1996; Ekvall, 1996; Siegel ve Kaemmerer, 1978). Görüldüğü üzere yenileşme uygulamalarının etkili bir şekilde gerçekleşmesini sağlayan iklim faktörleri yenileşme için önemlidir.

Mevcut araştırma, okullarda yenileşme uygulamalarına zemin hazırlayan yenileşme iklimine odaklanmıştır. Eğitim örgütlerinde yenileşme, öğretimin kalitesini geliştirmeye yönelik artan talepler, çevredeki hızlı değişimler ve okul kaynaklarındaki azalmalar okulları yenileşmeye zorlamıştır (Pihie, Asuimiran ve Bagheri, 2014). Okullarda yeniliklerin geliştirilmesi, benimsenmesi ve uygulanması okulun gelişimini anlamada önemli bir rolü bulunmaktadır. Okullarda yenileşme iklimi okul topluluğunun yeniliklere hazır olma durumunu, örgütsel amaçlara ulaşmak için yeni bilgi, uygulama ve iyileştirmelere yönelik istekliliklerini göstermektedir (Moolenaar vd., 2010; Moolenaar, Daly ve Sleegers, 2011). Bununla birlikte öğretmenlerin paylaşılan bir vizyona, bilgi çeşitliliğine sahip olmaları yenileşme için bir gerekliliktir. Okullardaki yenileşme iklimi büyük ölçüde müdür ve öğretmenlerin yaratıc1 fikirleriyle ilgilidir (West ve Sacramento, 2012). Yenilikçi düşüncenin hakim olduğu okullarda, yaratıcı fikirlere destek, farklı düşüncelere saygı ve liderlik ön planda tutulmaktadır. Bu durum okul çalışanlarının yaşamlarını zenginleştirmekte ve problem çözme becerilerini geliştirmektedir (Siegel ve Kaemmerer, 1978). Görüldüğü gibi ilgili tartışmalar okullardaki yenileşme ikliminin odağında, öğretmen ve okul müdürlerinin yenileşme sürecine yönelik motivasyonlarına vurgu yapmaktadir. 
Okullarda müdürler, yenileşme iklimini etkileyebilecek güç, yetki ve konuma sahiptir. Yenilikçi okul ortamında etkili liderlik davranışlarını sergileyen müdürler; öğretmenlerin ihtiyaçlarının farkında olmaları, okulun vizyonunu öğretmenler ile paylaşmaları ve etkili bir okul ortamı oluşturmaları gerekir (Kelley, Thornton ve Daugherty, 2005). Bununla birlikte okul yöneticilerinin öğretim odaklı olması, kararları çalışanları ile bilikte alması ve çalışanların mesleki gelişimini desteklemesi gibi önemli görevleri bulunmaktadır (Van Den Berg ve Sleegers, 1996). Bu tür uygulamaların okullarda ne düzeyde gerçekleştirildiğini ortaya koymak önemlidir.

Bu noktada yenileşmenin ön koşulu olarak görülen okullarda yenileşme iklimini ölçmeye yönelik çalışmaların yapılmadığı söylenebilir. Alanyazında genellikle Bryk, Camburn ve Luis'in (1999) geliştirdikleri ve daha sonra Moolenaar, Sleegers ve Daly (2011) tarafından yeniden gözden geçirilen ölçme aracında, öğretmenlerin yenilikleri denemeye yönelik isteklilikleri, değişime açık olmaları ve risk almaları boyutları ele alınmıştır. Bu bakımdan mevcut çalışmanın okuldaki yenileşme iklimini kapsamlı olarak ölçen ilk araç olması bakımından önemlidir. Yenileşme iklimi, çalışanların yaratıcı fikirlerinin desteklenmesi, yenileşmeye sağlanan kaynak ve olanaklar, öğretmenlere tanınan özgürlük ve özerklik, işbirliği ve uyuma dayanan takım çalışmalarını içermektedir. Bu açıdan okullarda yenileşme iklimine ilişkin algı veya görüşlerin belirlenmesi ve yenileşme iklimine yönelik problemlerin ortaya çıkarılmasını gerektirmektir. $\mathrm{Bu}$ bağlamda geliştirilen mevcut ölçme aracı okullarda yenileşme iklimine yönelik var olan durumun incelenmesini amaçlamaktadır.

\section{Yöntem}

$\mathrm{Bu}$ araştırma okullarda yenileşme iklimin ölçülmesine ilişkin bir ölçek çalışmasıdır. Ortaöğretim kurumlarında çalışan öğretmenlere yönelik "Okullarda Yenileşme İklimi Ölçeği" geliştirme süreçleri ve çalışma grubunun demografik özellikleri aşağıda verilmiştir. 


\section{Çalışma Grubu}

Araştırmanın çalışma grubunu 2016-2017 öğretim yılının bahar döneminde Ankara İli Yenimahalle İlçesindeki mesleki ve teknik ortaöğretim kurumlarında gerçekleştirilmiştir. Ölçek geliştirme sürecinde geçerlik ve güvenirlik analizlerinin örneklem büyüklügüne ilişkin olarak yazında görüş birliğinin olmadığı ifade edilebilir. Ancak ölçek geliştirme sürecinde Açımlayıcı Faktör Analizi (AFA) yapılabilmesi için Kline (2005) ölçekteki madde sayısının minimum iki katı kadarını yeterli görürken, Bryman ve Cramer (2012) madde sayısının minimum beş katı örneklem büyüklüğüne ulaşılması gerektiğini belirtmektedir. Bu kapsamda taslak ölçeklerin ön uygulaması hedef evren içerisinde 10 liseden seçilen 250 öğretmen üzerinde yapılmıştır. Ön uygulama sonrası geri dönen 210 anket formu içerisinde 193 ölçek formu değerlendirmeye alınmıştır. Araştırma grubunu 117 kadın ve 76 erkek gönüllü öğretmen oluşturmaktadir.

\section{Ölçek Geliştirme Süreci ve Verilerin Toplanması}

Okullarda yenileşme iklimi ölçeğinin geliştirilmesi sürecinde Yenilikçilik İklimi Modeli (Remneland-Wikhamn ve Wikhamn, 2011), Yenilikçilik İklimi Modeli (Scott ve Bruce, 1994), Örgütlerde Yeniliğe Destek Algısı Modeli (Siegel ve Kaemmerer, 1978), Takım İklimi Envanteri (Anderson ve West, 1996), KEYS modeli (Amabile vd., 1996), Yaratıcı İklim Modeli (Ekvall, 1996) ve Yenilikçilik İklimi Modeli (Montes vd., 2004) referans alınmıştır. Bu çalışmalarda kullanılan/değinilen ortak özellikler çerçevesinde 63 ifadeden oluşan bir madde havuzu oluşturulmuştur. Madde havuzundaki ifadelere katılımcıların katılım derecelerini belirlemek için (1-Hiç katılmıyorum, 2 Katılmıyorum, 3-Orta düzeyde katılıyorum, 4-Katılıyorum, 5-Tamamen katılıyorum) şeklinde 5'li likert derecelendirmesi yapılmıştır.

Yenileşme iklimi ölçeği taslak formundaki maddelerin amaca hizmet edip etmediğini belirlemek amacıyla görünüş ve kapsam geçerliğine başvurulmuştur. Ölçmede "görünüş geçerliği", alan uzmanlarının öznel yargılarını taşıyan ve ölçme aracının amaca ne düzeyde hizmet ettiğini belirleyen bir geçerlilik türüdür. Kapsam geçerliliği ise, ölçme aracının 
içeriğinin beklenilen davranışları ne derecede ölçtüğünü gösteren diğer bir geçerlilik türüdür (Balc1, 2013). Yenileşme iklimi ölçeklerinin görünüş ve kapsam geçerliliğinin saptanmasında tez danışmanı, eğitim yönetimi ile ölçme ve değerlendirme alanındaki uzmanların görüş ve önerileri alınmıştır. Bu çerçevede alan uzmanlarının ölçme aracının maddelerinin ölçülmek istenilen yapıyı ölçüp ölçmediğine ilişkin görüşleri dikkate alınarak gerekli düzeltmeler yapılmıştır. Ön uygulama öncesi için oluşturulan taslak ölçme aracının ilk bölümünde katılımcıların kişisel bilgilerine (cinsiyet, yaş, kıdem), ikinci bölümünde okullarda yenileşme iklimi (54 madde) düzeylerine yönelik ifadeler yer almıştır.

Ölçme aracının yapı geçerliliği için Açımlayıcı Faktör Analizi (AFA) ve Doğrulayıcı faktör Analizine (DFA) başvurulmuştur. AFA aynı yapıyı veya niteliği ölçen değişkenlerin bir araya gelmesiyle az sayıda faktör ile açıklanmaktadır (Balcı, 2013). Verilerin çözümlenmesinde faktör analizinin yapılabilmesi için $\mathrm{KMO}$ (Kaiser-Mayer-Olkin) güvenirlik katsayısının en az .60, Barlett Küresellik testinin ise p<.05 olması gerekmektedir. Araştırmacılar, faktör yük değeri için minimum sınırın .30 olması gerektiğini belirtmektedir. Ayrıca faktörlerin açıkladığı varyans yüzdesinin ise en az \%30 olması gerekmektedir (Büyüköztürk, 2011). Bu araştırmada faktörlerin yük değerleri için alt sınır .30 olarak belirlenmiştir. DFA ise, ileri düzey araştırmalarda örtük değişkenlere dayanan kuramların test edilmesinde kullanılmaktadır (Balcı, 2013). DFA'da modelin uyumu, uyum indeksleri aracilığıly belirlenmektedir. Araştırmalarda yaygın olarak kullanılan ve raporlanan uyum indeksleri X2/sd değeri, CFI, GFI, AGFI ve RMSEA değerleridir (Çokluk, Şekercioğlu ve Büyüköztürk, 2016; Lomax ve Schumacker, 2004; Sümer, 2000).

Yenileşme iklimi ölçme aracının güvenirliğini belirlemede ise Cronbach's Alpha Katsayısı ve düzeltilmiş madde toplam korelasyonları uygulanmıştır. Bu çerçevede Büyüköztürk (2011) madde toplam korelasyonu değerlerinin en az .30 olmasının maddelerin ayırt ediciliğinde iyi bir ölçüt olduğunu belirtmektedir. Bu araştırmada da maddelerin ayırt ediciliği için .30 değeri alt sınır olarak benimsenmiştir. 


\section{Bulgular}

\section{Açımlayıcı Faktör ve Güvenirlik Analizi}

Okullarda yenileşme iklimi ölçeğinin AFA analizlerinin incelendiği tablo 1 'de, KMO değeri .94 ve Barlett Küresellik testi anlamlı $(\mathrm{p}<.05)$ bulunmuş ve verilerin faktör analizi için uygun olduğuna karar verilmiştir. Bu noktada, ölçeğin yapı geçerliğini incelemek üzere, yapılan AFA eğik döndürme sonucunda ölçeğin beş faktörden oluştuğu belirlenmiştir. Bu faktörlerden herhangi birisine girmeyen, yalnız başına faktör oluşturan 6 madde ve binişik olan 11 madde değerlendirme dişında bırakılmıştır. Daha sonra uygulanan güvenirlik analizi sonucunda ise madde toplam korelasyonları .30'un altında olan 5 madde değerlendirme dişında bırakılarak geçerlik ve güvenirlik analizleri yinelenmiştir. Geçerlik ve güvenirlik analizi sonucunda yenileşme iklimi ölçeği 32 maddeden oluşmuştur.

Tablo 1'de okullarda yenileşme iklimi ölçeğinin açımlayıcı faktör ve güvenirlik analizleri incelendiğinde, 9 maddeden oluşan "yenileşmeye destek" boyutunun faktör yük değerleri .63 ile .78 arasında sıralanmış, boyut toplam varyansın \%20.88'ini açıklamıştır. Yenileşmeye destek boyutunun güvenirlik analizine bakıldığında ise, madde toplam korelasyonları .67 ile .86 arasında siralanmakta ve Cronbach Alpa güvenirlik katsayısı $\alpha=.95$ 'tir. Okullarda yenileşme ikliminin ikinci faktörünü oluşturan "kaynaklar ve olanaklar" boyutunda maddelerin faktör yük değerleri .63 ve .88 arasında yer almıştır. Bu boyut toplam varyansın yaklaşık \%15.56'sını açıklamış ve 6 maddeden oluşmuştur. Bu boyutun madde toplam korelasyonları .73 ile .86 arasında dağılmış ve güvenirlik katsayısı $\alpha=.94$ olarak bulunmuştur.

Yenileşme iklimi ölçeğinin üçüncü boyutu oluşturan 6 maddelik "inisiyatif alma" maddelerinin yük değerleri .61. ile .78 sıralanmış ve toplam varyansın \%14.86'sını açıklamıştır. Bu boyutun madde toplam korelasyonları .73 ile .86 arasında değişmiş ve güvenirlik katsayısı $\alpha=.93$ olarak bulunmuştur. 
Tablo 1. Yenileşme İklimi Ölçeği maddeleri yapı geçerliği ve güvenirlik analizleri

\begin{tabular}{lll}
\hline Maddeler & $\begin{array}{l}\text { Madde } \\
\text { Faktör } \\
\text { Yükleri }\end{array}$ & $\begin{array}{l}\text { Madde } \\
\text { Toplam } \\
\text { Korelasyonu }\end{array}$ \\
& & \\
\hline Yenileşmeye Destek & & \\
\hline 1-Öğretmenlerin gelişimi için zümre toplantıları önemsenir. & .71 & .67 \\
2-Yeni fikirler geliştirme konusunda öğretmenler cesaretlendirilir. & .67 & .78 \\
3-Yeni öğretim tekniklerini kullanan öğretmenler desteklenir. & .74 & .81 \\
4-Yeni fikirlerin gelişimi için öğretmenlere geri bildirim verilir. & .75 & .82 \\
5-Öğretmenlerin yeteneklerini geliştirmelerine rehberlik edilir. & .76 & .85 \\
6-Girişimci öğretmenler desteklenir. & .77 & .86 \\
7-Özgün fikirler takdir edilir. & .78 & .82 \\
8-Yeni fikir geliştirilen öğretmenler ödüllendirilir. & .63 & .76 \\
9-Öğretmenlerin yeni uygulamaları yaşama geçirmeleri desteklenir. & .64 & .80 \\
\hline Açlanan varyan: $\% 20,88$ & & \\
\hline
\end{tabular}

\begin{tabular}{lll}
\hline Açıklanan varyans: \%20,88 $\quad \alpha=.95$ & & \\
\hline Kaynaklar ve Olanaklar & .63 & .79 \\
\hline 10-İhtiyaç duyulan yeni kaynaklar (araç-gereç, bilgi vb.) zamanında temin & & .80 \\
edilir. & .68 & .83 \\
11-Yeni fikirlerin uygulanması için yeterli süre verilir. & .73 & .80 \\
12-Yeni proje uygulamaları için doğrudan kaynak sağlanır. & .78 & .86 \\
13-Yeni öğretim uygulamalarını geliştirme fırsatları sunulur. & .70 & .84 \\
14-Yeni uygulama kararları zamanında alınır. & .75 & .83 \\
15-Yeni bilgi teknolojilerini kullanma imkânı sağlanır. & & \\
\hline Açılanan varyans: \%15.56 $\quad \alpha=.94$ & & \\
\hline İnisiyatif Alma & .66 & .77 \\
\hline 16-Beklenmedik durumlarda öğretmenlerin inisiyatif almaları beklenir. & .61 & .74 \\
17-Öğretmenlerin görevleriyle ilgili risk almaları özendirilir. & .73 & .85 \\
18-Görevlerin farklı yollarla yapılmasına tolerans gösterilir. & .78 & .86 \\
19-Yenilikçi uygulama kararlarında hiyerarşiden çok uzmanlığa önem & & \\
verilir. & .72 & .83 \\
20-Yapılan hatalar birer öğrenme fırsatı olarak görülür. & .63 & .73 \\
21-Öğretmenler görevleriyle ilgili yeni uygulamaları denemekten & & \\
çekinmezler. & & \\
\hline
\end{tabular}

\begin{tabular}{|c|c|c|}
\hline Açıklanan varyans: \%14.86 & & \\
\hline \multicolumn{3}{|l|}{ Yenileşmeye Açıklık } \\
\hline 22-“Eski köye yeni adet getirme!” inancı hâkimdir. & .72 & .59 \\
\hline 23-Yeni teknolojilere sıcak bakılır. & .82 & .64 \\
\hline 24-Çalışanlar yenilikçi değişimlere açıtır. & .88 & .76 \\
\hline 25-Rutin uygulamaların dışına çıkılmaz. & .73 & .60 \\
\hline Açıklanan varyans: $\% 9.05 \quad \alpha=.83$ & & \\
\hline \multicolumn{3}{|l|}{ Takım Çalışması ve Uyum } \\
\hline 26-Sürekli iş birliği vardır. & .50 & .61 \\
\hline 27-İletişim kanalları açıktır. & .61 & .70 \\
\hline 28-Bilgi paylaşılır. & .67 & .84 \\
\hline 29-Uzlaşma kültürü bulunmaktadır. & .71 & .83 \\
\hline 30-Sorumluluk paylaşılır. & .67 & .82 \\
\hline 31-Öğretmenler birbirini anlama çabasına sahiptir. & .65 & .78 \\
\hline 32-Öğretmenler arasında "Bu projeyi başarabilirim." görüşü hâkimdir. & .49 & .64 \\
\hline \multicolumn{3}{|l|}{ Açıklanan varyans: $\% 12.87 \alpha=.91$} \\
\hline Toplam varyans $=\% 73.23 \quad$ Bartlett' KüresellikTesti $=6243.07(\mathrm{p}<.05)$ & .94 & $\alpha=.95$ \\
\hline
\end{tabular}


"Takım çalışması ve uyum", yenileşme ikliminin dördüncü boyutunu oluşturmuştur. Faktör yük değerleri .49 ile .71 arasında dağılmış olan bu boyut, toplam varyansın \%12.87'sini açıklamıştır. Takım çalışması ve uyum boyutunun madde toplam korelasyonları .61 ile .84 arasinda değişmiş ve güvenirlik katsayısı $\alpha=.91$ 'dir. Okullarda yenileşme ikliminin son boyutu ise "yenileşmeye açıklık" olarak adlandırılmıştır. $\mathrm{Bu}$ boyutun maddelerinin faktör yük değerleri 72 ile 88 arasında dağıldığı görülmüştür. Dört maddeden oluşan bu boyut, toplam varyansın \%9.05'ini oluşturmuştur. Yenileşmeye açılık boyutunun madde korelasyonları .59 ile .76 arasında değişmiş ve güvenirlik değeri $\alpha=.83$ 'tür. Yenileşme iklimi ölçeğinin tüm maddelerinin açılamış olduğu toplam varyans $\% 73.23$ olup güvenirlik katsayıs1 .95 'tir.

\section{Doğrulayıcı Faktör Analizi}

Açımlayıcı faktör analizi sonucunda oluşan faktörleri doğrulamak amacıyla DFA yapılmıştır. Yenileşme iklimi ölçeği doğrulayıcı faktör analizinin diyagramı, standart regresyon ve hata değerleri şekil 1'de gösterilmiştir. Yenileşme iklimi ölçeği doğrulayıcı faktör analizi sonuçlarına göre, veri uyumu için hesaplanan Ki-kare değerinin serbestlik derecesine oranı $(\mathrm{X} 2 / \mathrm{sd}=1,65)$ mükemmel uyumu, GFI ve AGFI dişındaki uyum indekslerinin $(\mathrm{RMSEA}=.051, \mathrm{GFI}=.86, \mathrm{AGFI}=.83, \mathrm{CFI}=$ .97) iyi uyumu göstermektedir. AGFI ve GFI değerlerinin düşük olması, örneklem büyüklügünün yeterli düzeyde olmamasından kaynaklanmaktadır (Jöreskog ve Sörbom, 2001; Sümer, 2000). Yenileşme İklimi Ölçeği yol diyagramı şekil 1'de verilmiştir. 
Mahmut Polatcan

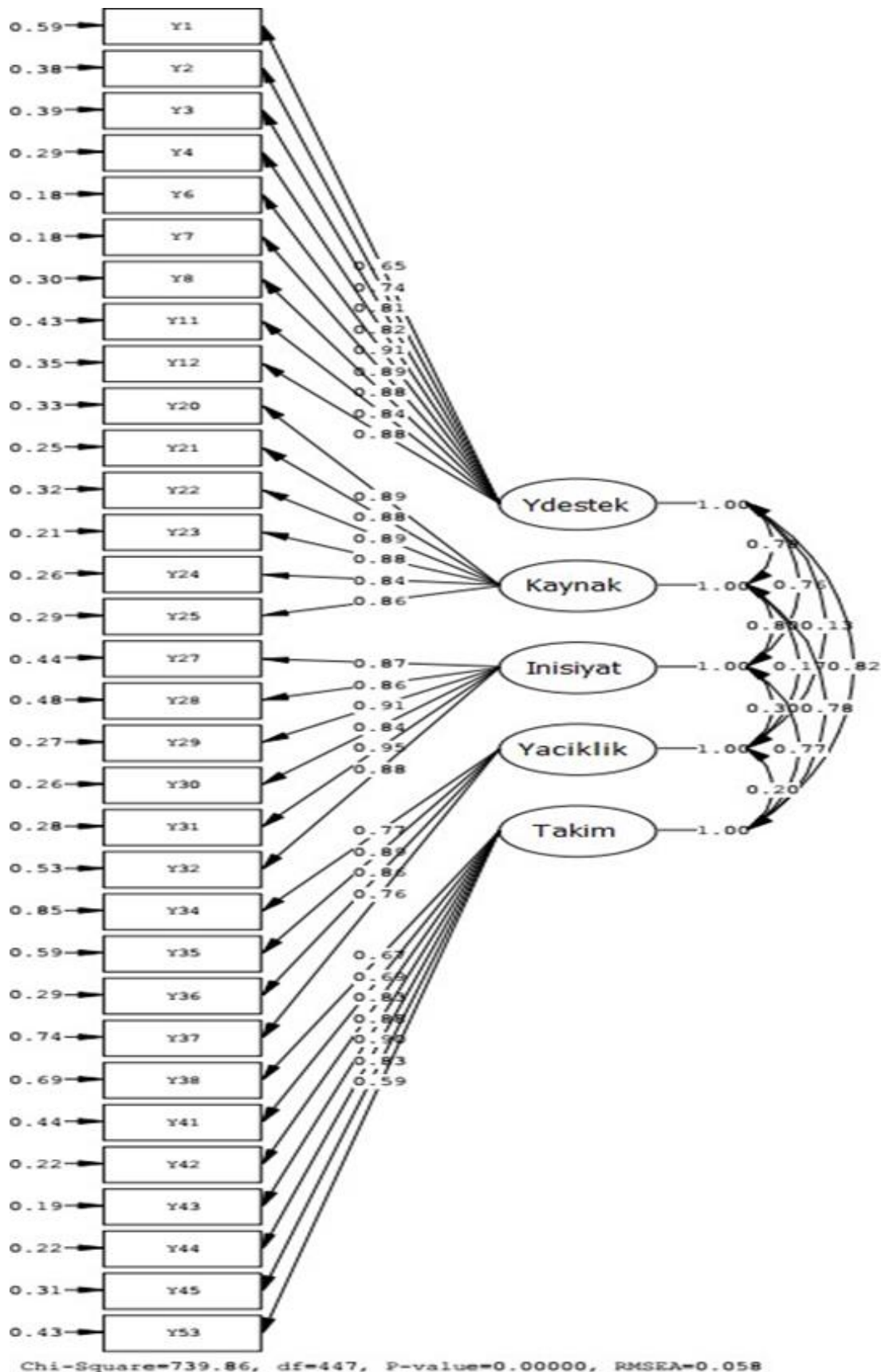

Şekil 6. Yenileşme İklimi Ölçeği doğrulayıcı faktör analizi sonuçları 


\section{Tartışma}

Okullarda yenileşme iklimi uygulamalarının belirlenmesine yönelik geliştirilen mevcut ölçme aracının yapı geçerliği için yapılan AFA sonucunda, ölçme aracındaki maddelerin faktör yüklerinin .30 yüksek olduğu ve ölçme aracının beş boyut oluşturduğu görülmüştür. 32 maddelik ölçeğin açıklamış olduğu toplam varyans \%73.23'tür. Madde analizi sonucunda oluşan faktörlerdeki ifadelerin kapsamı, kuramsal çerçeve doğrultusunda sırasıyla yenileşmeye destek, kaynak ve olanaklar, inisiyatif alma, yenileşmeye açıklık, takım çalışması ve uyum şeklinde boyutlandırılmıştır. Yenileşmeye destek varyansın \%20.88'ini, kaynaklar ve olanaklar boyutu varyansın \%15.56'sını, inisiyatif alma varyansın \%14.86'sını, yenileşmeye açıklık varyansın \%9.05'ini, takım çalışması ve uyum varyansın \%12.87'sini oluşturmaktadır. Bu bağlamda faktörlerdeki maddelere ilişkin faktör yükleri, açıklanan varyanslar dikkate alındığında, ölçeğin yapı olarak geçerli bir ölçme aracı olduğu söylenebilir. Nitekim maddelerin faktör yük değerleri ve boyutların ölçülmek istenen özelliği ölçebilme niteliği taşıdığı ve her bir maddenin ayırt edici olduğu görülmüştür. Öte yandan açımlayıcı faktör analizi sonuçlarının doğrulanması amacıyla yapılan doğrulayıcı faktör analizi sonucunda uyum indekslerinin iyi uyum gösterdiği görülmüştür. Söz konusu uyum indeksleri dikkate alındığında oluşturulan modelin açımlayıc faktör analizi sonuçlarıyla örtüştüğü saptanmıştır.

Yenileşme İklimi Ölçeğinin güvenirlik analizi sonucunda, Ölçeğin tümüne ilişkin ilişkin Cronbach Alfa güvenirliğinin .95 olduğu görülmüştür. Ölçme aracının boyutlarının iç tutarlılık katsayıları yenileşmeye destek .95, kaynaklar ve olanaklar .94, inisiyatif alma .93, yenileşmeye açıklık .83, takım çalışması ve uyum .91 şeklinde sıralanmıştır. Bu sonuçlara bağlı olarak ölçeğin güvenirlik ve iç güvenirlik katsayılarının .70'in üzerinde olması ölçeğin güvenilir bir ölçme aracı olduğu kabul edilmektedir (Büyüköztürk, 2011; Pallant, 2013). Bu sonuçlar ölçme aracının bir bütün olarak ve alt boyutlarının da kendi içlerinde tutarlı olduğunu göstermektedir. Ayrıca maddelerin düzeltilmiş madde toplam korelasyonlarının minimum düzeyin ( $\mathrm{r}=.30)$ üzerinde olduğu, tüm maddelerin ölçülmek istenen özellikleri taşıdığı söylenebilir. 
Okullar yaratıcı ve yenilikçi düşüncelerin üretildiği kurumlar arasında gelmektedir. Dolayısıyla okulların amaçlarına ulaşmak için yenilik yapmak zorundadır. Yeniliklerin başarıyla uygulanmasında yenileşmeye destek verme, fikirleri özgürce ifade etme, yeterli kaynak ve zaman sağlama, takım çalışması ve uyum gibi yenileşme koşullarının oluşmasına bağlıdır (Van Den Berg ve Sleegers, 1996). Bununla birlikte okullarda yönetici ve öğretmenlerin başarılı olmasında uygun örgütsel iklim önemli rol oynamaktadır. Öyle ki sağlıklı okul ikliminde yönetici ve öğretmenlerin görevlerini başarılı bir şekilde yerine getirmeleri beklenmektedir. Bu bağlamda bu çalışma işletme literatüründe kapsamlı bir biçimde ele alınan yenileşme ikliminin eğitim araştırmalarına katkı sunacağı söylenebilir. Mevcut çalışma, okul geliştirme odaklı güncel eğitim araştırmalarına yönelik farklı bir bakış açısı getirmektedir. Bununla birlikte öğretmen ve okul müdürlerinin algı ve davranışlarını ölçebilecek bir araç olması nedeniyle alan yazına katkı sağlamaktadır. Bu araştırmanın sınırlılıklarına gelince, mevcut ölçme aracı ortaöğretimdeki öğretmen görüşleri çerçevesinde geliştirilmiştir. İlerleyen süreçte yapılacak araştırmalar okul yöneticileri, farklı eğitim kademeleri ve okul türleri üzerinde uygulanabilir. 


\title{
EXTENDED ABSTRACT
}

\section{Innovativeness Climate in Schools Scale Validity and Reliability Study *}

\author{
Mahmut Polatcan
}

Karabük University

This study focuses on innovative climate, which forms the base for innovation practices. In this respect, this scale development study is of importance as it is the first instrument to measure the innovative climate in the school. Therefore, it can be said that modernization in schools which are considered as a modern enterprise has similarities with the enterprise organizations in many aspects. Innovative climate includes team works based on supporting the creative ideas of employees, resources and facilities provided for innovation, freedom and autonomy for teachers, and cooperation and adaptation. In this respect, it is necessary to identify the perception and opinions about innovative climate in schools and to reveal the problems related to innovative climate. This developed instrument aims to examine the current situation of innovative climate in schools.

\section{Method}

This is a scale development study that aims to measure innovative climate in schools. The study was performed in vocational and technical secondary schools in Yenimahalle district of Ankara province during the spring term of 2016-2017 academic year. In this context, preimplementation of draft scales was carried out with 250 teachers selected from 10 upper secondary schools. 210 participants responded the questionnaires, but 193 scale forms were evaluated. The study group consisted of 117 female and 76 male volunteer teachers. Both Exploratory Factor Analysis (EFA) and Confirmatory Factor Analysis (CFA) were applied for construct validity. Considering reliability analysis, Cronbach Alpha reliability coefficients were examined. 


\section{Results}

EFA revealed that the factor loadings of the items in the measuring instrument were higher than .30 and the measurement instrument had five dimensions. The total variance explained by the 32-item scale was $73.23 \%$. The emerging dimensions were labelled in line with the theoretical framework, such as support for innovation, resources and facilities, taking initiative, openness to innovation, and teamwork and adaptation. The dimensions and their total variance were as follow: Support for innovation (20.88\%); resources and facilities (15.56\%); taking initiative $(4.86 \%)$; openness to innovation $(9.05 \%)$; team work and adaptation $(12.87 \%)$. In this context, considering factor loads and factors explained in the factors, it can be said that the scale is a valid measurement tool. In addition, the results of the exploratory factor analysis showed that the fit indexes were in good agreement $(\mathrm{X} 2 / \mathrm{sd}=1,65$, RMSEA $=.051$, GFI $=.86$, $\mathrm{AGFI}=.83, \mathrm{CFI}=.97)$. On the other hand, as a result of the reliability analysis of Innovative Climate, the Cronbach Alpha reliability coefficient was found to be .95 . The internal consistency coefficients of support for innovation, resources and facilities, taking initiative, openness to innovation, team work and adaptation were listed as .95, .94, .93, .83, and.91 respectively.

\section{Conclusion}

It can be said that the developed measurement instrument is a valid and reliable. In this respect, the present study provides a different perspective on current literature that has focused on school development. Besides, this instrument contributes to the available literature as it can measure the perception and behavior of teachers and school principals. Considering the limitations of this study, the instrument was developed within the framework of teachers' opinions in secondary education. Further studies can be conducted with school administrators, different educational levels and school types. 


\section{Kaynakça / References}

Ahmed, P. K. (1998). Culture and climate for innovation. European Journal of Innovation Management, 1(1), 30-43. doi:10.1108/14601069810199131

Amabile, T. M. (1983). The social psychology of creativity: A componential conceptualization. Journal of Personality and Social Psychology, 45(2), 357-376. doi:10.1037/0022-3514.45.2.357

Amabile, T. M. (1996). Creativity in context: Update to the social psychology of creativity. CO, US: Westview Press.

Amabile, T. M., Conti, R., Coon, H., Lazenby, J., ve Herron, M. (1996). Assessing the work environment for creativity. Academy of Management Journal, 39(5), 1154-1184. doi:10.5465/256995

Anderson, N., ve West, M. A. (1996). The team climate inventory: Development of the tci and its applications in teambuilding for innovativeness. European Journal of Work and Organizational Psychology, 5(1), 53-66. doi:10.1080/13594329608414840

Balcı, A. (2013). Sosyal bilimlerde araştırma: Yöntem, teknik ve ilkeler. Ankara: Pegem Akademi.

Bryk, A., Camburn, E., ve Louis, K. S. (1999). Professional community in chicago elementary schools: Facilitating factors and organizational consequences. Educational Administration Quarterly, 35(5), 751781. doi:10.1177/0013161X99355004

Bryman, A., ve Cramer, D. (2012). Quantitative data analysis with ibm spss 17, 18 ve 19: A guide for social scientists. London ve New York: Routledge.

Büyüköztürk, Ş. (2011). Sosyal bilimler için veri analizi el kitabı. Ankara: Pegem Akademi.

Chen, C. J., Huang, J. W., ve Hsiao, Y. C. (2010). Knowledge management and innovativeness: The role of organizational climate and structure. International Journal of Manpower, 31(8), s.848-870. doi:10.1108/01437721011088548

Çokluk, Ö., Şekercioğlu, G., ve Büyüköztürk, Ş. (2016). Sosyal bilimler için çok değişkenli istatistik: Spss ve lisrel uygulamaları. Ankara: Pegem Akademi. 
Damanpour, F. (1992). Organizational size and innovation. Organization Studies, 13(3), 375-402. doi:10.1177/017084069201300304

Ekvall, G. (1996). Organizational climate for creativity and innovation. European Journal of Work and Organizational Psychology, 5(1), 105123. doi:10.1080/13594329608414845

George, J. M., ve Zhou, J. (2001). When openness to experience and conscientiousness are related to creative behavior: An interactional approach. Journal of Applied Psychology, 86(3), 513-524. doi:10.1037/0021-9010.86.3.513

Hunter, S. T., Bedell, K. E., ve Mumford, M. D. (2007). Climate for creativity: A quantitative review. Creativity Research Journal, 19(1), 6990. doi:10.1080/10400410709336883

Jaiswal, N. K., ve Dhar, R. L. (2015). Transformational leadership, innovation climate, creative self-efficacy and employee creativity: A multilevel study. International Journal of Hospitality Management, 51, 30-41. doi:10.1016/j.ijhm.2015.07.002

Jöreskog, K. G., ve Sörbom, D. (2001). Lisrel software version 8.51. Chicago: Scientific Software International.

Kelley, R. C., Thornton, B., ve Daugherty, R. (2005). Relationships between measures of leadership and school climate. Education and Science, 126(1), 17-26.

Kline, R. B. (2005). Methodology in the social sciences. In (2 ed.). New York, US: Guilford Press.

Lomax, R. G., ve Schumacker, R. E. (2004). A beginner's guide to structural equation modeling. New Jersey London: Lawrence Erlbaum Associates, Inc.

Mathisen, G. E., ve Einarsen, S. (2004). A review of instruments assessing creative and innovative environments within organizations. Creativity Research Journal, 16(1), 119-140. doi:10.1207/s15326934crj1601_12

Montes, F. J., Moreno, A., ve Fernández, L. (2004). Assessing the organizational climate and contractual relationship for perceptions of support for innovation. International Journal of Manpower, 25(2), 167-180, doi:10.1108/01437720410535972 
Moolenaar, N. M., Daly, A. J., ve Sleegers, P. J. C. (2010). Occupying the principal position: Examining relationships between transformational leadership, social network position, and schools' innovative climate. Educational Administration Quarterly, 46(5), 623-670. doi:10.1177/0013161X10378689

Moolenaar, N. M., Daly, A. J., ve Sleegers, P. J. C. (2011). Ties with potential: Social network structure and innovative climate in dutch schools. Teachers College Record, 113(9), 1983-2017.

Oldham, G. R., ve Cummings, A. (1996). Employee creativity: Personal and contextual factors at work. The Academy of Management Journal, 39(3), 607-634. doi:10.5465/256657

Pallant, J. (2013). Spss survival manual: A step by step guide to data analysis using ibm spss (5 ed.). New York: McGraw-Hill Education.

Pihie, Z. A. L., Asuimiran, S., ve Bagheri, A. (2014). Entrepreneurial leadership practices and school innovativeness. South African Journal of Education, 34(1), 1-11. doi:10.15700/201412120955

Remneland-Wikhamn, B., ve Wikhamn, W. (2011). Open innovation climate measure: The introduction of a validated scale. Creativity and Innovation Management, 20(4), 284-295. doi:doi:10.1111/j.14678691.2011.00611.x

Ren, F., ve Zhang, J. (2015). Job stressors, organizational innovation climate, and employees' innovative behavior. Creativity Research Journal, 27(1), 16-23. doi:10.1080/10400419.2015.992659

Scott, S. G., ve Bruce, R. A. (1994). Determinants of innovative behavior: A path model of individual innovation in the workplace. Academy of Management Journal, 37(3), 580-607. doi:10.5465/256701

Siegel, S. M., ve Kaemmerer, W. F. (1978). Measuring the perceived support for innovation in organizations. Journal of Applied Psychology, 63(5), 553-562. doi:10.1037/0021-9010.63.5.553

Somech, A., ve Drach-Zahavy, A. (2011). Translating team creativity to innovation implementation: The role of team composition and climate for innovation. Journal of Management, 39(3), 684-708. doi:10.1177/0149206310394187

Sümer, N. (2000). Yapısal eşitlik modelleri: Temel kavramlar ve örnek uygulamalar. Türk psikoloji Yazıları, 3(6), 49-74. 
Van Den Berg, R., ve Sleegers, P. (1996). Building innovative capacity and leadership. In K. Leithwood, J. Chapman, D. Corson, P. Hallinger, A. Hart (Ed.), International handbook of educational leadership and administration (pp. 653-699). Dordrecht: Springer.

West, M. A., ve Sacramento, C. A. (2012). Creativity and innovation: The role of team and organizational climate. In M. D. Mumford (Ed.), Handbook of organizational creativity (pp. 359-385). San Diego: Academic Press.

*Bu çalışma, yazar tarafından hazırlanan "Okullarda Sosyal Sermaye ile Yenileşme İklimi Arasındaki İlişki" isimli doktora tez çalışması için geliştirilen bir ölçme aracıdır. Katkılarından dolayı Sayın Prof. Dr. Ali BALCI'ya teşekkür ederim.

\section{Kaynakça Bilgisi / Citation Information}

Polatcan, M.(2019). Okullarda yenileşme iklimi ölçeğinin geçerlik ve güvenirlik çalışması. OPUS-Uluslararası Toplum AraştırmalarıDergisi, 11(18), 364-383. DOI: 10.26466/opus.533385 